\title{
Indonesian Language Learning Methods in Australian Elementary Schools
}

\author{
Rahmi Fhonna $^{1}$, Yunisrina Qismullah Yusuf ${ }^{2}$ \\ ${ }^{1}$ Universitas Islam Negeri Ar-Raniry, Indonesia \\ ${ }^{2}$ Universitas Syiah Kuala, Indonesia \\ Correspondence concerning this article should be addressed to Yunisrina Qismullah Yusuf, Department \\ of English Education, Faculty of Teacher Training and Education, Universitas Syiah Kuala, Banda Aceh, \\ Indonesia.E-mail: yunisrina.q.yusuf@unsyiah.ac.id
}

\begin{abstract}
Previous studies have largely focused on the importance, problems, and challenges of teaching second languages in Australian schools, but very few have investigated the teaching methods used in the classroom to do so. Therefore, the purpose of this study is to identify the methods applied by teachers who teach Indonesian as a second language in one of the public primary schools in South Australia to enable their Australian students to comprehend the instruction in the Indonesian class. The data were collected through observational field notes and video recordings of three class meetings from two teachers. Evidence gives validity to analysis, and thus the data were analysed using the transcription conventions as proposed by Burns, Joyce \& Gollin (1996). The results showed that the most frequently used methods by the teachers in teaching Indonesian to the Early Year level students were TPR (total physical response) and GTM (grammar-translation method). TPR was useful as the act of moving around seemed to help the children remember the vocabulary. Furthermore, GTM helped the teachers clarify the meanings of words and sentences for the students by translating them into their first language, i.e. English. These methods were not taught in isolation but were integrated by the teachers with other methods such as the direct method and audio-lingual method. The reflection of this teaching practice is considered a worthwhile contribution for other teachers who are also teaching Indonesian in other countries and as additional insights to immerse themselves in their language teaching practice. Moreover, considering the benefits of becoming bilingual, such as in communication, culture, cognition, character, curriculum, and economy, schools should provide more training for teachers to help them be able to use the best techniques in teaching the second language to enable and empower them to integrate other languages into their classes.
\end{abstract}

Keywords: primary school, second language, integrated learning, teaching methods

\section{Introduction}

Teaching a second language for children requires specific methods to meet the needs of students in the classroom. The school environment plays an important role in fostering second language learning. Accordingly, Mickan (2006) notes that a school is a place where students are taught to be part of the social communities; and this is done through the language learning setting. Consequently, students attend schools to explore their abilities through the social and educational experiences offered in a school community. It is believed that each student has a different way of learning and unique characteristics since they grow up in different circumstances. These include the school environment, like buildings and their facilities, peers, and most importantly, teachers. Therefore, becoming a teacher at any school level is a demanding profession in terms of preparing themselves as facilitators and also organizing various activities to nurture the students' cognitive development, social skills, and creativity.

Consequently, a great deal of research has also promoted the benefits of learning a second or foreign language, especially starting from early childhood; among them are cognitive, social-emotional, academic, career, and 
cultural benefits (Baker, 2000; Pransiska, 2017; Yusuf, 2009). Therefore, to start teaching other languages at a young age is encouraged. Trautner (2019) explains that children who can speak more than one language may have a stronger ability to focus on one thing and change their response if necessary, as shown in this study later where the word 'rhinoceros' (English) is replaced with badak (Indonesian). This process indicates their cognitive flexibility (Fajerson, 2017). Trautner (2019) further describes that when a bilingual child communicates, the languages in the brain compete to be stimulated and selected, and this requires attention and the ability for the brain to be flexible. The interference pushes the brain to choose the most appropriate language to use, and this mind workout supports its cognitive muscles. Furthermore, this practice of the brain requires self-control (Trautner, 2019). Self-control is furthermore one of the important traits in childhood classrooms because, later in life, this skill allows people to regulate their behaviour and actions to achieve their life goals (Milyavskaya \& Inzlicht, 2017). In terms of social and cultural benefits, to be able to speak more than one language may broaden one's enculturation, create a deeper sense of multiculturalism, and allow them to experience the "language worlds" that are associated with the languages they speak (Yusuf, 2009, p. 318).

Even though second language education is a matter of constant public debate in Australia (Mellor, 2009), the NALSPP (National Asian Language and Studies in Schools Program) offers foreign languages to be taught in public schools, such as Auslan, Chinese, French, German, Indonesian, Italian, Japanese, Korean, Modern Greek, Spanish, and Vietnamese (www.decd.sa.gov.au). Bianco and Slaughter (2009, p. 64) have intensely captured the reasons for teaching second languages in Australian schools as follows:

"The principal reason is to do with the deepest purposes of education itself, to instill knowledge, to deepen understanding, to stimulate reflection, and to foster skills. Languages are intimately linked to the essentially humanistic, cultural, and intellectual reasons for making education compulsory. Bilingualism can foster more reflective and imaginative dispositions in citizens, and the principles of democratic discourse, participation, and opportunity which Australia proclaims also find resonance with language study since the great bulk of humanity lives in societies and continues traditions forged outside of English". (Bianco \& Slaughter, 2009, p. 64)

They also state that language education should be driven by educational, cultural, and intellectual purposes, rather than limited by the aims to the employment industry. Mellor (2009) further affirms that nurturing bilingual skills, especially those of Australians, does not only benefit people economically but also serves the intellectual and cultural needs of the language learners.

In Australia, selecting professional teachers is the main focus to meet the need of the students' development at any stage of school. The AITSL (Australia Institute for Teaching and School Leadership) is an institute that often collaborates with the Minister of Education to provide professional teachers (http://intan.com.au/about/ professional-standards). This institute offers several criteria for teachers' recruitment regarding their proficiency. It is very important to hire teachers who are capable of identifying with the students and how they learn, and creating and maintaining supportive and safe learning environments.

Learning with a professional teacher also seems to have beneficial impacts on the students since the teacher can better understand the students. As mentioned previously, teachers play crucial roles in the success of students' learning. School should be a place to feed students' imagination and engage their creativity. Once they are interested in learning, they will be successful at school. This is because students need to become proficient in a wide range of tasks and knowledge domains (Lapan, et.al, 2003).

What is more, Kohler and Mahnken (2010) mention that Indonesian is the third most studied language in public schools in Australia. Several teachers teaching this course in public schools have personal experiences related to Indonesian in terms of its culture and other social interactions. They also explain why Indonesian has been established in Australian schools. the main reasons are economic matters, educational and personal advantages, and possible employment opportunities. They further clarify that, although Australian students' interest has been declining in learning this language since 2001, quantitative data have shown that Indonesian is still a major language taught in Australian schools (Kohler \& Mahnken, 2010). Indonesian, therefore, is still taught as a class subject and not incorporated into other lessons such as math, science, and English. 


\section{Learning a Second Language at an Early Age}

Schumann (1986) states that some students at an early age learn the second language indisputably as they believe that it is a source of pleasure; this is the same sense of pleasure that they experience when they are engaged in free play. Sometimes, students are even found to try rigidly to create new forms of vocabulary for words that they are learning if necessary (Schumann, 1986). Learning a second language encourages cognitive development, creativity, and thinking in children; if they are more exposed to the foreign language in meaningful social surroundings, they will find more opportunities to learn because social environments stimulate their mental processes (Munoz \& Forero, 2011). At this point, the teachers are required to encourage students' motivation to build a better learning environment. What is more, both students and teachers have to form a mutual relationship to achieve the purpose of the educational process (Gablinske, 2014; Han, 2012).

Language is a means utilized by both students and teachers to socialize efficiently in order to develop emotions, knowledge, ability (Lindquist, MacCormack \& Shablack, 2015), as well as creating events and social actions (Verga \& Kotz, 2013). Therefore, the language is used to deliver the message as well as transmit any information through communication. Integrated language learning then is designed to enable students to comprehend the target language easily. The interactions that arise in the classroom are classified as a mutual relationship between teachers and learners to achieve the goal of the pedagogical context (Hall \& Walsh, 2002, p. 187).

Various studies have shown that learning a second or foreign language at an early age brings about benefits to the individual; hence, it should be studied continuously throughout his or her educational levels (Paradis, Kirova \& Dachysyn, 2009; Prieto, 2009; Yusuf, 2009; Yusuf, Asyik, Yusuf \& Rusdi, 2017). Bamford \& Mizokawa (1991) even claim that some students who learn a second language are more resourceful and superior at resolving complex problems compared to those students who do not. Moreover, bilingual children are also found to be more motivated to learn foreign languages compared to monolinguals, as is the case of students from bilingual families and students from Russian monolingual families (Komlósi, 2017). Waterworth (2016, p. 162) exquisitely elucidated this, saying:

"The language and culture we first learn (L1) define and determine our place and our identity. They create our sense of ourselves, our feelings, opinions, and values. Learning a new language (L2) provides us with the opportunity to expand our horizons, to understand a little of speakers of that language, and to gain a better sense of ourselves and our world".

And thus, exposing children to other languages improves their intercultural competence; this means that they are more aware of the global community and more familiar with diversity because they can recognize other existing culture(s) besides their own through language(s) (Curtain \& Dahlberg, 2004). In a modern society today, diversification, globalization, and multiculturalism are important compenents in a country's education system (Achaeva, Daurova, Pospelova \& Borysov, 2018). They stimulate the interest of learners in new knowledge and help them embrace diverse viewpoints from of the world.

\section{Integrated Learning in Teaching Second Languages}

Silver, Strong, and Perini (2000) emphasized that integrated learning indicates the profound meaning of the teaching process as it affects the improvement of a school's curriculum and helps in the assessment of students' work. At the same time, teachers play important roles to formulate an appropriate approach to help students become more self-aware and competitive learners. In this view, teachers should provide an impressive classroom environment to motivate students while learning a second language. The decision to teach integrated language should also be supported by the curriculum planning as a part of the methodology because integrated lessons help students make connections across curricula. Curriculum planning in communicative language teaching is very essential regarding what is to be taught and also how it is to be taught since both processes are integrated (Nunan, 1989a).

Among the benefits of integrated learning, some challenges arise from this program. The greatest challenges come from teachers themselves. Banegas (2012) asserts that teachers, who are in charge of implementing integrated learning in schools, can fail the program if they lack awareness and knowledge about how to apply it in their classes. He further adds that teachers have to fully understand what is expected of them when executing integrated learning in schools because this program requires that the content and language teachers work 
together. Mehisto (2008) has provided some suggestions for overcoming the challenges faced by teachers, including that schools that implement integrated learning must provide enough training opportunities, give support for immersion centers, and offer sufficient teaching materials to the teachers. The school, therefore, should apply an appropriate curriculum that fits the needs of students and motivates them to be better (Banegas, 2012).

\section{Methods for Teaching the Second Language}

There are also various methods used to teach second language learners. Mora (2017) listed the ten most recognized and commonly used methods for teaching a second or foreign language; they are the GTM (Grammar-Translation Method), Direct Method, Reading Method, Audio-lingual method, Community Language Learning, Silent way, Communicative Method, Functional Notional Method, TPR (Total Physical Response), and Natural Method.

The Grammar-Translation Method is a method in which the lessons are taught mostly in the students' first language, with some active use of the target (second/foreign) language. Specifically, the students are directed to translate words from the first language into the target one. This means that the students are expected to be more familiar with the grammar of their native language and this will help them speak and write their native language better (Larsen-Freeman, 2008; Qing-xue \& Jin-fang, 2007). This method is found to be effective in large classes with EFL students of different language ability levels (Aqel, 2013). This is different from the Direct Method, in which the lessons are instructed in the target language and the first language is never used.

The Reading Method involves one of the skills of learning a language, followed by the importance of the historical knowledge of the country where the language is spoken. Meanwhile, the Audio-lingual Method is a method in which language learning is based on habit formation and adopts a dependence of mimicry, memorizating set phrases, and over-learning the target language.

Community Language Learning, furthermore, illustrates how students work together to improve the aspects of a language they are keen to learn; meanwhile, the teacher acts as a counselor, while the learner is seen as a client and collaborator (the counselling approach). This method is surely different from the Silent Way, which makes use of silence as a teaching method. Here, teachers are encouraged to be silent most of the time during the teaching and learning process but learners are stimulated to speak as much as possible.

The Communicative Method, additionally, is the continuous acquisition of the target language to achieve learners' communicative purposes. This is different from the Functional Notional Method because it highlights the communicative purposes of speech acts and focuses on the purposes for which the target language is used.

To focus on the coordination of language and physical movement, the teacher might use TPR (Total Physical Response); hence, the students are not forced to speak, but they are provided with individual readiness periods. While teaching, the teacher just gives a command to the students in the target language while performing it together with them. This method is beneficial for attracting students' attention while learning, and it is a good way to teach vocabulary easily.

Another method that is often used by teachers is the Natural Method, where language learning is seen as a reproduction of the way humans naturally acquire their first language. Moreover, to expose children to the language being taught is essential. Meshkat and Karami (2016, p. 84) claim that "unless children are exposed to language, they will not acquire it". Accordingly, teachers need to wisely select the methods they will use to teach a second or foreign language to their students by selecting an appropriate approach to achieve the teaching objectives. This is because young and adult language learners process information in their first language differently whilst learning. Thomson (2010) explains that children first begin to sort out words involving concrete objects; on the other hand, adult learners can deal with abstract ideas. Of course, children learn at different stages of development, and activities that the teachers design in the classroom needs to address their cognitive, psychomotor, language, and social development (Malia, 2004). That is why when children are introduced to a second or foreign language in the classroom, teachers need to present vocabulary for objects that they can touch or see (Cameron, 2001). Teachers must use words that are easy for them to understand (Silver, Strong \& Perini, 2000). By having a clear conceptual image of these things or actions, it will 
be simpler for children to process the information in the second or foreign language.

Previous studies have largely focused on the importance, problems, and challenges of teaching second languages in Australian schools (Bianco \& Slaughter, 2009; Chen, 2015; Kelabora, 1978; Kohler, 2014; Liddicoat \& Kohler, 2012; Mellor, 2009), but none have investigated the teaching methods used in the classroom to do so. Therefore, this study intends to fill in this research gap. The research question for this study is: What are the methods used by teachers when teaching Indonesian as a second language in Australian schools? By collecting data through the qualitative approach using observations and tape recordings, this study can shine a light on the existent teaching and learning processes that makes second language teaching and learning feasible for Australian students in the classroom.

\section{Methodology}

\section{Participants}

This study used qualitative design to carry out the research. Under the monitoring of the South Australian government, we collected data in two different public primary schools that are situated in Adelaide, South Australia. These schools have 13-14 classrooms for different levels of students. Moreover, Indonesian is taught as a second language in the schools; it has been taught since 2004 as the schools have chosen it as a Language Other Than English (LOTE). Indonesian, thus, is taught at all level of classes with a focus on integrating the language across the curriculum. Thus, we chose these schools as the locations of our research for data collection.

During data collection, we found no Australians of Indonesian descendants, children of Indonesian parents working or studying in Australia, or Indonesian children adopted by Australian natives studying at the two schools. There were also no teachers of Indonesian descendants or Indonesian themselves teaching at the schools. Most of the students are native Australians (of European descendants) and others are from nonEnglish speaking backgrounds (or NESB) countries such as Greece, Congo, and Italy. Each class at the schools consists of approximately 20 students. There are three different levels of students' classes: Early Years, Middle Primary, and Upper Primary.

To succeed in the language teaching-learning processes, the Indonesian curriculum is designed based on the government's curriculum guidelines; it combines both the government curriculum and the curriculum that is designed by the language team at each school. As a consequence, the combination sustains the students' language learning system. A focus is also placed on raising student awareness about the country and its culture; the culture of the target language country is incorporated to emphasize an in-depth understanding of the language itself. Diversified materials can be found for each year level and term. The curriculum is revised at the end of each term where it is necessary.

The teachers combine materials that are obtained from the resources such as the internet and related books. The materials taught are distinguished for each level of students, and lesson plans and any supporting materials are prepared to ease the teaching-learning process before teaching.

\section{Data Collection Procedures}

The data was collected through observational field notes and tape recordings from two teachers and two classes, with consent from both the teachers and students. The consent form was handed out in person by the first and third researchers of this paper to the school, the teachers, and students who were the participants of this research. Through observations and tape or audio recordings, it is expected that we could gain a clear picture of the methods applied by the teachers for teaching Indonesian as a second language. Students from two different primary schools were taken as the participants for this research; the pupils were 7 to 8 years old and in Term 3. One English teacher from each primary school was observed while she was teaching in her class. This made a total of two teachers being observed over six class meetings.

The teachers taught Indonesian at their schools. They are Australians with no Indonesian background and are both in their forties. They have been teaching Indonesian for about three years and have visited Indonesia a few 
times for holidays, workshops, and training on teaching Indonesian to speakers of other languages. In this paper, the first teacher is coded as T1 and the second teacher is coded as T2.

In the observational field notes, the first and third authors (without participation) stood and walked around the classroom without getting too close to the subjects to avoid interference in the teaching and learning process. The observation allowed us to check for nonverbal expressions of feelings, interactions between individuals and groups (i.e. how they communicated with each other), and examine the time used for each activity done in the class (Schmuck, 1997). Even though their presence caught the attention of the students, since they did not intermingle with their class activities, they were not a distraction to the students.

\section{Data Analysis}

In the analysis, the observational field notes were assembled, summarized, and presented in a way that reveals the crucial findings or features of this study. From the tape recordings, the conversations that took place in the classroom were transcribed using the coding conventions adapted from Burns, Joyce, and Gollin (1996). They are as presented in Table 1.

\section{Table 1}

Coding Conventions

\begin{tabular}{ll}
\hline \multicolumn{1}{c}{ Coding } & \multicolumn{1}{c}{ Meaning } \\
\hline[ & overlapping turns \\
$\ldots$ & a short pause (approximately 1 second) \\
\{\} & contextual information accompanying a text \\
$(())$ & uncertain transcription \\
$((?))$ & indecipherable \\
$<>$ & altered transcription used for confidentiality \\
$\left({ }^{\prime . . . ')}\right.$ & English translation \\
Italicized words & Indonesian \\
\hline
\end{tabular}

Note. Adapted from "I see what you mean: Using spoken discourse in the classroom" by A. Burns, H. Joyce, and S. Gollin, 1996, p. 61-62. Copyright 1996 by Macquarie University NCELTR.

The evidence from data transcription serves as the validity of the analysis. Mason (1997, p. 89) states that "a judgment about whether data analysis is valid is a judgment about whether or not it measures, explicates or illuminates whatever it claims to measure, explicate or illuminate". The purpose is to pose analysis, discussion, and conclusions in such a way that readers can assess the researchers' explanations (Ryan, 2006). And thus, after the transcription was done, event analysis (Erickson, 1992) was implemented, which was meant to find specific beginnings and endings of events by finding specific boundaries that denote the events. In this research, the events focused on the different methods the teachers used to teach Indonesian as a second language to young Australian children in the classroom. Therefore, the analysis of the conversations between teacher and student in the classroom were conducted carefully, to obtain specific results regarding the topics discussed.

\section{Results}

\section{Teaching Indonesian as a Second Language}

In each meeting with $\mathrm{T} 1$ and $\mathrm{T} 2$, the teachers prepared the materials earlier before the classes. In the preparation session, the teachers asked the students to sit in a circle on the floor. The purpose was to create a relaxing learning situation to easily adjust the students to the learning environment. For the class taught by the first teacher, the topic that day was "Animals" and it was a continuation of the previous lesson's topic. Meanwhile, for the class taught by the second teacher, the topic for that day was "Colours". It was observed that since the teachers both taught a continuation of the previous lesson's topic, the whiteboards were already 
plastered with pictures of various animals before the class started for $\mathrm{T} 1$ and there were cards of different colors on the teacher's table in T2's class.

At the beginning of the classes, to get the students' attention, both teachers started questioning the students on what they had learned earlier on the topics of "Animals" for the class of T1 and "Colors" for the class of T2. The process of both classes was similar from beginning to end. Therefore, in this paper, we are reporting the recordings from T1's class meeting with successive activities that were conducted in her class to show the methods used in the teaching and learning process. In the extracts, T1 refers to the teacher, $\mathrm{S}$ is a student (each student is coded with a number from 1-20) and SS refers to more than one student talking at the same time. Extract 1 shows the discourse that took place in the class of T1 being observed in this research.

Extract 1 (01.00 - 04.48):

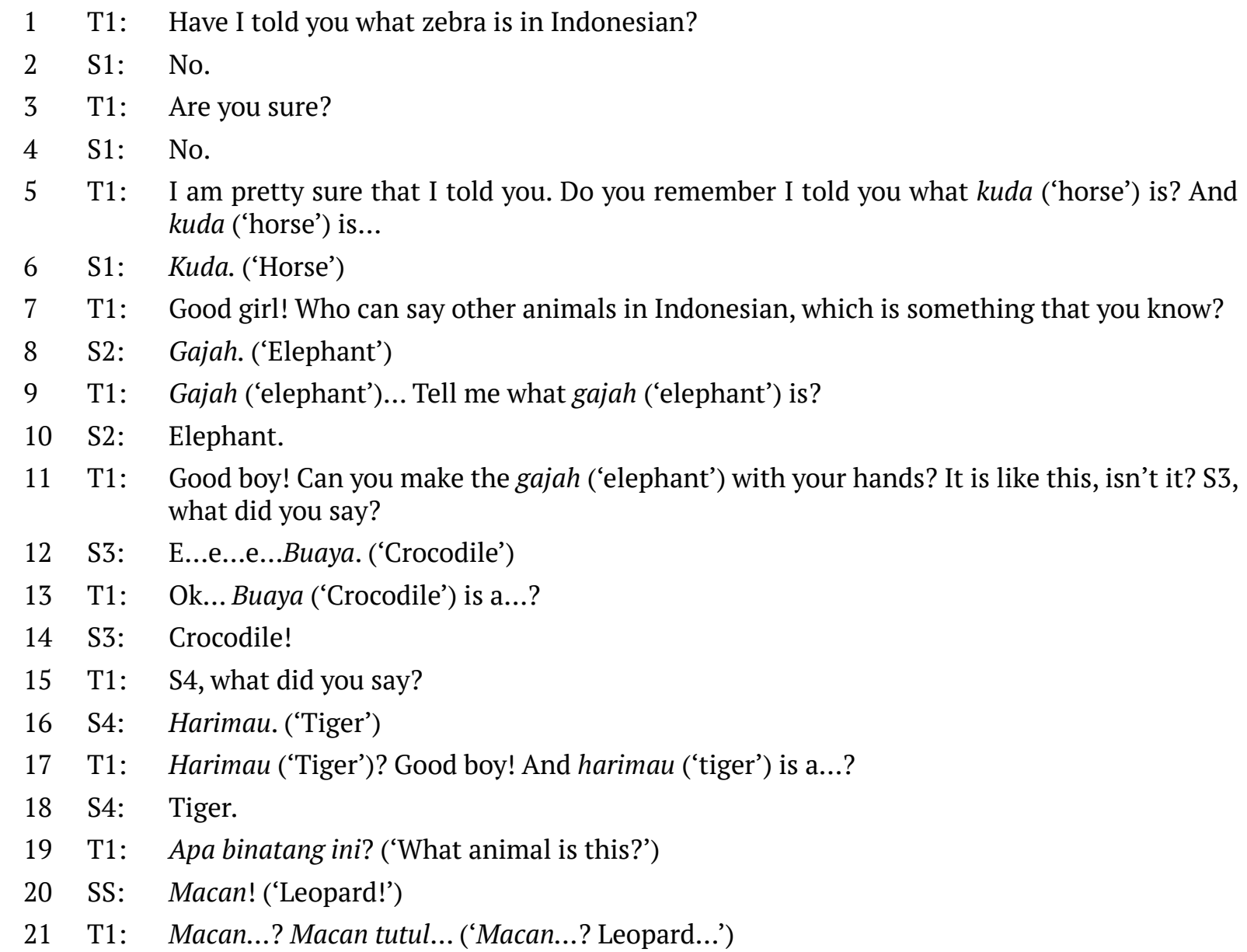

It can be seen in Extract 1 that the conversation started with a simple question as the teacher asked the students about the animals' names in the target language (i.e. Indonesian) while showing the pictures on the whiteboard. In line 5 , she tried to remind the students that the intended word had already been taught in the previous lesson when S1 could not answer her question. She also translated the word into the students' first language to emphasize meaning. Accordingly, S1then was able to repeat the word with the correct pronunciation. The teacher continued asking questions to students in their first language. At this point, she used open-ended questions to stimulate the students' knowledge of the topic selected. As seen in line 10, S2 answered the question with the correct word as well. This means that the strategy used is on the mark.

Moving on to the next step, the teacher tried to engage the student's attention by imitating the animal's character using her hands as shown in line 11 in Extract 1. Hence, from lines 1 to 21, the interactional concept occurred simply as she was attempting to stimulate the students' minds by asking the names of animals in the target language. In the last few lines, she even tried to construct a complex sentence in the target language by asking, Apa binatang ini? ('What animal is this?'). All students were able to reply to the question correctly. Turn-taking in the conversation also happened fluently. Nunan (1989b) mentions that the identification of 
turn-taking is a crucial part of interaction management. This learning novelty can also occur because of the topic being learned that day, which was about animals and their names in Indonesian. Therefore, the questionanswer interaction would be a common activity in this context. Nevertheless, it can be concluded then that learning integrated language helps students acquire a comprehension of the target language.

Extract 2 (05.25 - 12.45):

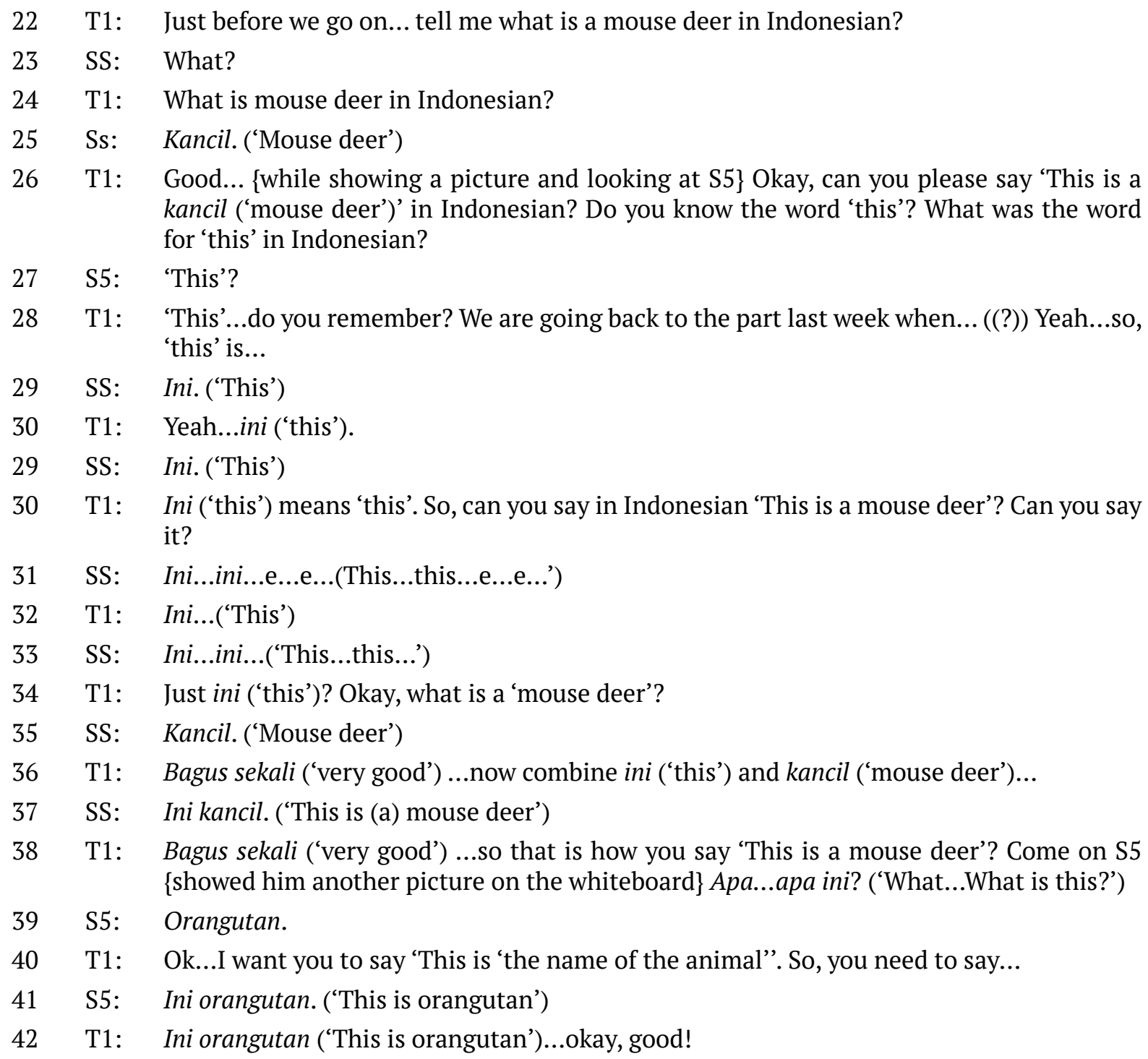

Extract 2 shows the complex pattern that was used by the students in the target language. In line 26, the teacher emphasized the word 'this' and asked the students to translate it. However, the students could not remember the appropriate meaning of the word in the target language. She then tried to help them recall the lesson she taught in their previous meetings, which had examples of the meaning of 'this' in Indonesian. After she shared these examples, students remembered it and could translate the word. She had pronounced the translation repeatedly with the students mimicking her pronunciation to reiterate the meaning of the word.

Thus, lines 30 to 42 illustrate an in-depth explanation of the word that is provided separately to enable the students to synchronize the pattern of both languages, resulting in the construction of a well-structured sentence in the target language. Line 36 exemplifies how the teacher replied to the students' answers in the target language as an approval signal. Regarding this view, Dalton-Puffer (2007) notes that whole class interaction activities consist of the teacher conducting a dialogue with the class with its marked tripartite Initiation-Response-Feedback structure. By preparing the model of the sentence, the students became familiar with the pattern given and were able to create the sentence in the target language. 
To become more familiar with the words and sentences in the target language, the introduction of another element to enrich them was continued. Using the same method and media, the teacher expanded the questions as in Extract 3:

\section{Extract 3 (13.00-20.15):}

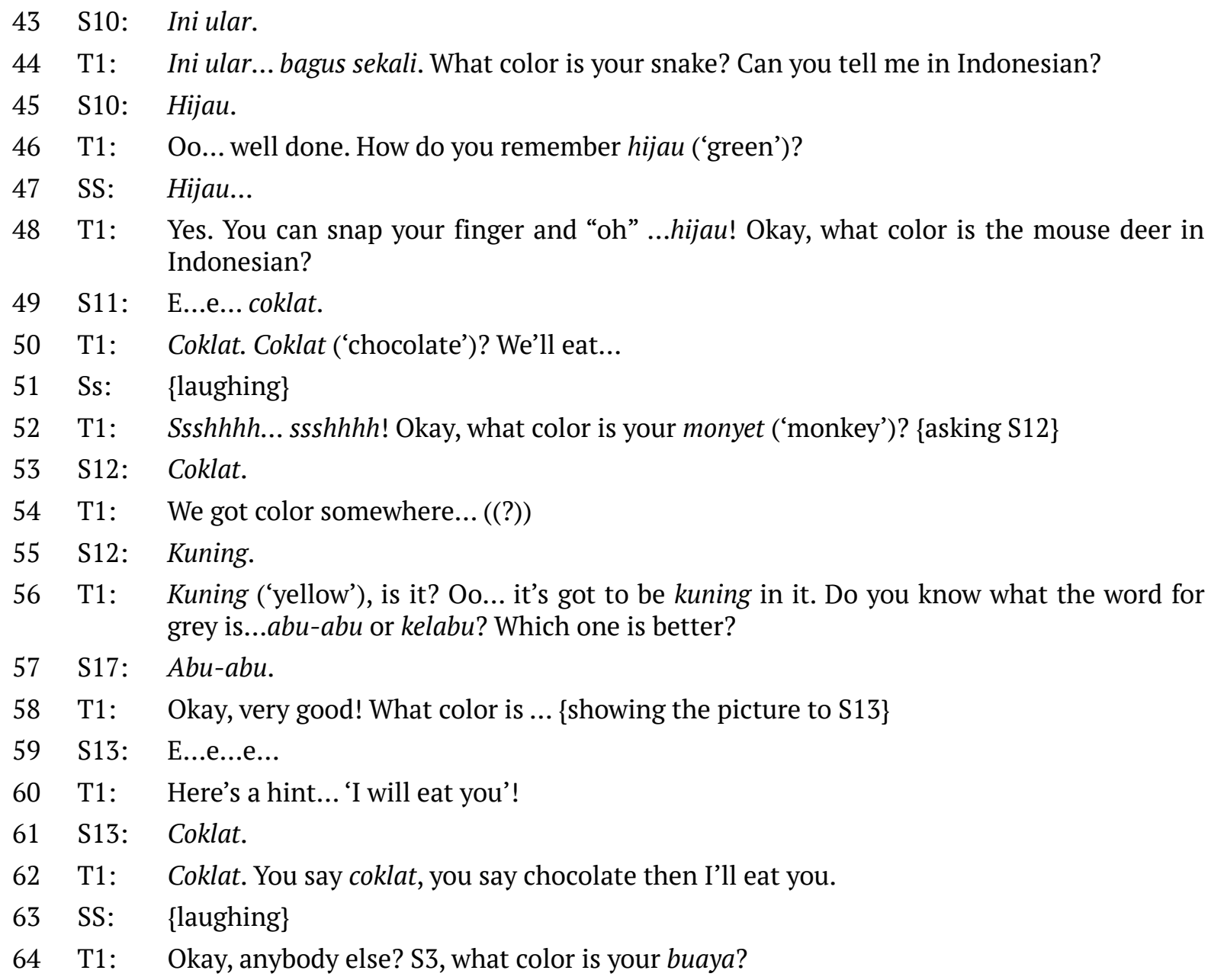

From Extract 3, it is clear that the focus of the teaching moved on to colors. In line 45, S10 was able to answer the question about the color directly. To remind the students that colors had been taught in their previous lesson, the teacher demonstrated the action of hitting her finger to produce the sound /au/to present the word ' 'hijau' /hidgau/. This kind of method is known as TPR (total physical response) in which the students learn based on the coordination of speech and actions together (Hill, 2005). In lines 49 and 50, it was shown that the pronunciation of the word coklat/t5oklat/ that has almost the same sound as 'chocolate' in English. Therefore, she emphasized the word in ' $a$ ' and not ' $\mathrm{e}$ ' at the end of coklat/t5oklat/. At this point, the students were becoming familiar with this color as it was easy to remember due to its resemblance to a word in English, as shown in line 61. At first, S13 could not recall the word to describe the color of the animal that was shown in the picture by the teacher. However, the student accurately recalled the intended vocabulary once the teacher hinted, 'I will eat you' in line 60. Thus, the turn-taking mechanisms in this extract happened fluently and the class situation was well controlled by the teacher.

Near the end of class, the students learned about Indonesian grammar, and the conversations between the teacher and her students were seen to be more complex compared to the previous extracts at the beginning of class. In this part, they had to construct the sentence that consisted of the S + P + O (Subject + Predicate + Object) structure, such as Saya melihat harimau 'I see a tiger', in which saya is the subject, melihat is the predicate and harimau is the object. The teacher pretended that they were in a jungle. This interaction is shown in Extract 4. 
Extract 4 (20.45-28.30):

65 T1: Listen carefully. I'm going to put on the music now. When the music is on... \{some students were talking\}. When the music is on, I want you...Oh dear, you two (raised her fingers to two students), go sit by the door. I'm giving instruction but you two are busy talking! \{After the students sat at the corner for a time-out, she continued her explanation\}. So, when the music is on, we...we are going to find and going to look around Dalam Hutan, right? When the music stops, you need to pace and I'm going to ask you which animal you can see. Do you remember what the word see is?

66 SS: Or..

67 T1: What? I will give you the first letter... \{wrote a letter on the whiteboard\}. A few letters then...

68 SS: Merah... merah muda!

69 T1: Can you guess again?

70 S7: Mel... mel...

71 T1: Melihat.

72 SS: Melihat!

73 T1: So, to say 'I can see a bird', how do you say that? \{paused\} Saya melihat and the name of your animal. So, you say saya melihat.

74 SS: Saya melihat...

75 T1: Okay...Bagus sekali ('very good')! Then put your animal's name after it. S4, what is your animal?

76 S4: Harimau ('tiger').

77 T1: Okay! So, when you see it, what are you going to say?

78 S4: Emmh...ee... Saya...say... mela...

79 T1: ...melihat...

80 S4: melihat...Saya melihat... eemm...harimau.

81 T1: Yeah...Well done!

Based on this extract, the students were trying to memorize the name of animals in the target language and further put them in a sentence based on the pattern that had been explained by the teacher. All of them succeeded in constructing a correct sentence grammatically.

\section{Indonesian as an Informal Integrated Teaching Model}

During our observation, it was identified that the schools were not allowed to teach Indonesian integrated with other school subjects by the South Australian Education Department. The lack of Indonesian teachers was one of the reasons for this. On the other hand, the schools formed an Indonesian committee that consists of four or five members. The teams have worked as Indonesian curriculum designers. The curriculum's content is cyclical and is revised every three years. Its material is combined with the South Australian Curriculum Standards and Accountability framework (SACSA) developed by the Department of Education and Children's Services (DECS 2005).

A vocabulary-based approach is the concept of the curriculum design, which is intended to allow the teachers to select the material that is taught to the students. From the Early Year level up to Upper Primary level, students are taught about the vocabulary and the expansion to phrases is uncommon. In the Early Year level, for instance, the content includes numbers, colors, and animals' names. In the next level, it includes forming simple sentences by using more complex vocabulary themes such as at home and at school.

As mentioned earlier, the teachers teach Indonesian in their classes and they do not incorporate it with other lessons such as math, science, and English. On the other hand, the teachers used to integrate Indonesian terms into organizational classes in the morning while checking students' attendance through greetings such as 
selamat pagi 'good morning', apa kabar? 'how are you?', and terima kasih 'thank you'. Another technique to help students be familiar with the Indonesian language is through the lists of numbers, colors, animals, and the name of months which are hung on the walls in the classes. What is more, the students are also introduced to the Indonesian culture through celebrating Indonesian Independence Day every August 17. On this day, both teachers and students participate in assembly performances by performing Indonesian art, Indonesian traditional costumes like batik, and Indonesian traditional games like layang-layang 'kite flying'. This is relevant to what the Indonesian coordinator explained to us during our preliminary study before data collection. We were told that both of the schools' commitment is to introduce Indonesia, not just its language but also its culture. The students in the schools also raised some money to be donated to orphanages in Bali, which is one of the provinces in Indonesia.

\section{Discussion}

In this study, we sought to answer the research question that investigated the methods used by two teachers for teaching Indonesian as a second language in Australian primary schools. We observed the Indonesian language teaching process and its informal integration in two of the public primary schools in South Australia. The analysis focused on the process of the Indonesian lesson taught by the Indonesian coordinators at the schools, respectively. The interactions that occurred during the lessons characterized a marked feature of students' apprenticeships into the Indonesian language. During the learning process, each student actively participated and was able to develop at every stage of learning to became familiar with the materials. They obtained an indepth understanding of the target language through pictures and the teacher's instruction. These can be seen through the vocabulary sets presented by the teachers (as can be seen in the extracts explained above as examples, especially in Extract 2 where the teacher changed the picture to attract students' attention and to trigger their understanding related to the topic explained) and the students were able to remember them well. At this point, the teachers successfully created situated-learning opportunities to engage students' attention.

Based on the observations, the teachers were able to maintain the interaction with the students until the end of the lesson. It could be seen through the students' enthusiasm for learning and their ability to understand and respond to the questions provided in the target language. The grammar-translation method is used by the teachers to enable students to comprehend the topic selected. Qing-xue and Jin-fang (2007) described how the grammar-translation method emphasizes the teaching of second language grammar and its principle technique is the translation from and into the target language. The implications of this method could be observed via the instructions given and the media used such as pictures and cards. In Extract 2, for instance, the teacher asked questions based on the pictures or cards shown, like the picture of a mouse deer and orangutan, and the students directly translated them into the target language. This method places the teachers as the centre of learning. Moreover, another method used by the teacher in teaching the course was TPR (Total Physical Response), which could be seen from the available extracts above. This kind of method was used to encourage the students to be more familiar with the material given.

The students, additionally, learned Indonesian through lists of words such as numbers, colors, animals' names, and months which were displayed around each classroom. It can be seen in Extracts 3 and 4 when the teacher tried to train the students to guess the colour, and the teacher just provided the first letter of the word (in Extract 4). The students then had to guess the rest of the letter to complete the intended word. This is considered to be a successful method for effortlessly enabling students to indirectly memorize the word in the target language. This is also a good way to teach the students to remember simple vocabulary as well as to help the teachers handle the class practically. Silver, Strong, and Perini (2000) state that with primary students, it is important to use words that are easy to understand. What is more, the concept of a vocabulary-based curriculum that is developed from the simple to the complex pattern is assumed to have a beneficial impact on students' learning processes. Once, we observed one of the students in the Early Year level who had difficulty spelling the word 'rhinoceros' while in an English lesson class. She then changed the word into the target language by filling in the blank with badak, which means rhinoceros in Indonesian. In this case, the student's remembrance of the target language illustrated that the Indonesian informal integrated teaching had a positive influence on enriching her vocabulary in the target language. 


\section{Conclusion}

Based on the results, we can conclude that the most used method by the teachers in teaching Indonesian to the Early Year level students was GTM (grammar-translation method), with some TPR (total physical response). GTM helped the teachers clarify the meanings of words and sentences by translating them into the first language of the students. The comprehension that the students received from this method helped them to picture the words or things precisely into their minds. Of course, both of these methods were not taught in isolation but were integrated by the teachers along with other methods. Consequently, schools should provide more teachers to teach Indonesian subjects in the future as we found that the students are enthusiastic about learning Indonesian as a second language. Even though the observation focused only on students at the Early Year level, their progress learning Indonesian was notable. The teachers successfully engaged the students' attention from the beginning until the end of the lesson.

Meanwhile, TPR was useful when the act of moving around was needed to provide clarification, such as in the last activity of Saya Melihat or 'I See' as if they were in the jungle. It easily created memorable meaning through movement and helped the children remember the vocabulary much easier rather than by just memorizing the words out of a textbook. By doing this activity, the students were expected to focus more on the teacher's commands that enabled them to easily understand the topic discussed. This can be seen at the beginning of Extract 4 where the teacher slowly directed the students to concentrate on what she described, and she chastized the students who lost their attention while she was explaining something.

Considering the benefits of becoming bilingual, such as in communication, culture, cognition, character, curriculum, and economy, schools should provide more training to assist teachers as they teach Indonesian, and other languages, in their classes. When designing the curriculum, the Indonesian committee at the schools should collaborate with the Indonesian coordinator from the South Australian Education Department. Consequently, the materials provided may be expanded so that it becomes comprehensive and more suitable for each level of students. The interactional process that we captured showed that both the teachers and students were successfully involved in the teaching-learning environment. Thus, for future research on this topic, we recommend that in-depth interviews be conducted with teachers teaching Indonesian in Australian primary schools. This is due to the time limitations of the study. By doing so, more data can be gained to support or elucidate the conclusions drawn from this study.

\section{Conflict of interest}

The authors declare that they have no conflict of interest.

\section{References}

Achaeva, M., Daurova, A., Pospelova, N., \& Borysov, V. (2018). Intercultural education in the system of training future teachers. Journal of Social Studies Education Research, 9(3), 261-281.

Aqel, I. M. (2013). The effect of using grammar-translation Method on acquiring English as a foreign language. International Journal of Asian Social Science, 3(12), 2469-2476.

Baker, C. (2000). The care and education of young bilinguals: An introduction for professionals. Cambrian Printers Ltd.

Bamford, K.W., \& Mizokawa, D. T. (1991). Additive-bilingual (immersion) education: Cognitive and language development. Language Learning 41(3), 413-429. https://doi.org/10.1111/j.1467-1770.1991.tb00612.x

Banegas, D. L. (2012). Integrating content and language in English language teaching in secondary education: Models, benefits, and challenges. Studies in Second Language Learning and Teaching, 2(1), 111- 136. https:// doi.org/10.14746/ssllt.2012.2.1.6

Bianco, J. L., \& Slaughter, Y. (2009). Second languages and Australian schooling. ACER Press.

Burns, A., Joyce, H., \& Gollin, S. (1996). I see what you mean: Using spoken discourse in the classroom. Macquarie University NCELTR. 
Cameron, L. (2001). Teaching languages to young learners. Cambridge University Press.

Chen, Z. (2015). Challenges of teaching Chinese in Australian schools: Lesson from beginning teacherresearchers. Journal of Language Teaching and Research, 6(5), 933-942. http://dx.doi.org/10.17507/jltr.0605.04

Curtain, H., \& Dahlberg, C. A. (2004). Languages and children. Making the match: New languages for young learners, grades $K$-8 (3rd ed.). Longman.

Dalton-Puffer, C. (2007). Discourse in content and Language Integrated Learning (CLIL) classrooms. John Benjamin's.

DECS (Department of Education and Children's services). (2005). $R$-10 language (alphabetic) teaching resources. Hyde Park Press.

Erickson, F. (1992). Ethnographic microanalysis of interaction. In M. LeCompte, W. Milroy \& J. Pressel (Eds.), The handbook of qualitative research in education (pp. 201-225). Academic Press.

Fajerson, A. (2017). Do bilinguals have more cognitive flexibility than monolinguals? [unpublished Bachelor's thesis]. Orebro University.

Gablinske, P. B. (2014). A case study of student and teacher relationships and the effect on student learning [Unpublished doctoral dissertation]. University of Rhode Island.

Hall, J. K., \& Walsh, M. (2002). Teacher-student interaction and language learning. Annual Review of Applied Linguistics, 22, 186-203. https://doi.org/10.1017/S0267190502000107

Han, Z. (2012). On the construction of an acceptable type of teacher-student relationship in a higher vocational college. IERI Procedia, 2, 77-82. https://doi.org/10.1016/j.ieri.2012.06.054

Hill, S. (2005). Whole-body learning. PRAXIS Fremdsprachenunterricht, 3, 28-35.

Kelabora, L. (1978). Continuing education for Indonesian language teachers in Victoria, Australia. Australian Journal of Teacher Education, 3(2), 52-71. http://dx.doi.org/10.14221/ajte.1978v3n2.5

Kohler, M., \& Mahnken, P. (2010). The current state of Indonesian language education in Australian schools. Education Services Australia Ltd.

Kohler, M. (2014). The teaching and learning of Indonesian in Australia: Issues and prospects. In N. Murray, \& A. Scarino (Eds.), Dynamic ecologies: A relational perspective on languages education in the Asia-Pacific region (pp. 169-181). Springer.

Komlósi, F. (2017). Motivation of Russian students towards the learning of English. Journal of Language and Education, 3(1), 23-33. https://doi.org/10.17323/2411-7390-2017-3-1-23-33

Lapan, R. T., Tucker, B., Kim, S-K., \& Kosciulek, J. F. (2003). Preparing rural adolescents for post-high school transitions. Journal of Counselling \& Development, 81(3), 329-342. https://doi.org/10.1002/j.1556-6678.2003. tb00260.x

Larsen-Freeman, D. (2008). Techniques and principles in language teaching. Oxford University Press.

Liddicoat, A., \& Kohler, M. (2012). Teaching Asian languages from an intercultural perspective: Building bridges for and with students of Indonesian. In X. Song \& K. Cadman (Eds.), Bridging transcultural divides: Asian languages and cultures in global higher education (pp. 73-99). University of Adelaide Press, Adelaide.

Lindquist, K. A., MacCormack, J. K., \& Shablack, H. (2015). The role of language in emotion: Predictions from psychological constructionism. Frontiers in Psychology, 6, 1-17. https://doi.org/10.3389/fpsyg.2015.00444

Mason, J. (2002). Qualitative researching (2nd ed.). Sage Publications.

Malia, E. (2004). Designing classroom activities for teaching English to children. TEFLIN Journal, 15(1), 58-73. http://dx.doi.org/10.15639/teflinjournal.v15i1/58-73

Mehisto, P. (2008). CLIL counterweights: Recognising and decreasing disjuncture in CLIL. International CLIL Research Journal, 1(1), 93-119.

Mellor, S. (2009). Second languages and Australian schooling. Research Development, 22, 2-5.

Meshkat, M., \& Karami, M. (2016). Child directed speech in SpongeBob Square Pants in its original English language and in its Persian-dubbed version. International Journal of Early Childhood Special Education, 8(1), 83-99. https://doi.org/10.20489/intjecse.239577

Mickan, P. (2006). Socialisation, social practice, and teaching. In P. Mickan, I. Petrescu \& J. Timoney (Eds.), Social practices, pedagogy, and language use: Studies in socialisation (pp. 7-23). Lythrum Press.

Milyavskaya, M., \& Inzlicht, M. (2017). What's so great about self-control? Examining the importance of effortful self-control and temptation in predicting real-life depletion and goal attainment. Social Psychological and Personality Science, 8(6), 603-611. https://doi.org/10.1177/1948550616679237

Mora, J. K. (2017). Second and foreign language teaching methods. http://moramodules.com/ALMMethods.htm

Munoz, M. E. M., \& Forero, M. A. V. (2011). Teaching English vocabulary to third graders through the application of the Total Physical Response Method. https://core.ac.uk/reader/71396210

Nunan, D. (1989a). Designing tasks for the communicative classroom. Cambridge University Press. 
Nunan, D. (1989b). Understanding language classrooms. Prentice-Hall International.

Paradis, J., Kirova, A., \& Dachysyn, D. M. (2009). Working with young children who are learning English as a new language. Alberta: Alberta Education.

Pransiska, R. (2017). Benefits of bilingualism in early childhood: A booster of teaching English to young learners. Advances in Social Science, Education and Humanities Research (ASSEHR), 58, 390-393. https://doi. org/10.2991/icece-16.2017.68

Prieto, V. H. (2009). One language, two languages, three languages...more? National Association for the Education of Young Children.

Qing-xue, L., \& Jin-fang, S. (2007). An analysis of language teaching approaches and methods. US-China Education Review, 4(1), 1-3.

Ryan, A. B. (2006) Methodology: Analysing qualitative data and writing up your findings. In M. Antonesa, H. Fallon, A. B. Ryan, A. Ryan, T. Walsh \& L. Borys (Eds.), Researching and Writing your thesis: A guide for postgraduate students (pp. 92-108). Maynooth Adult and Community Education.

Schmuck, R. (1997). Practical action research for change. IRI/Skylight Training and Publishing

Schumann, J. (1986). Research on the acculturation model for second language acquisition. Journal of Multilingual and Multicultural Development, 7(5), 379-392. https://doi.org/10.1080/01434632.1986.9994254

Silver, H. F., Strong, R.W., \& Perini, M.J. (2000). So each may learn: Integrating Learning styles and multiple intelligences. Association for Supervision and Curriculum Development.

Thomson, S. (2010). Teaching young learners: Adapting the classroom for YELLs. http://www.birmingham.ac.uk/ Documents/college-artslaw/cels/essays/younglearners/ThomsonYL.pdf

Trautner, T. (2019, January 28). Advantages of a bilingual brain: Teaching young children a second language is beneficial in many ways. MSU Extension Early Childhood Development. https://www.canr.msu.edu/news/ advantages_of_a_bilingual_brain

Verga, L., \& Kotz, S. A. (2013). How relevant is social interaction in second language learning? Frontiers in Human Neuroscience, 7, 1-7. https://doi.org/10.3389/fnhum.2013.00550

Waterworth, P. (2016). Teaching English in Asean: The voices of English Teachers in Asean nations. Indonesian Journal of Applied Linguistics, 5(2), 154-166. https://doi.org/10.17509/ijal.v5i2.1340

Yusuf, Y. Q. (2009). A case study on infant bilingual acquisition. Modern Journal of Applied Linguistics, 1(5), 303331.

Yusuf, Q., Asyik, A. G., Yusuf, Y. Q., \& Rusdi, L. (2017). “Listen, do, repeat, understand and remember”: Teaching English to very young children in Aceh. Iranian Journal of Language Teaching Research, 5(2), 113-132. 